\title{
Microencapsulação de probióticos por gelificação iônica interna
}

\author{
Microencapsulation of probiotic by internal ionic gelation
}

\author{
Augusto Tasch Holkem ${ }^{1}$, Graciele Lorenzoni Nunes ${ }^{2}$, Cristiane Franco Codevilla ${ }^{3}$ e Cristiano \\ Ragagnin de Menezes ${ }^{4}$
}

\author{
${ }^{1}$ Mestrando em Ciência e Tecnologia dos Alimentos, Universidade Federal de Santa Maria, RS, Brasil \\ ${ }^{2}$ Doutoranda em Ciência e Tecnologia dos Alimentos, Universidade Federal de Santa Maria, RS, Brasil \\ graci_nunnes@hotmail.com \\ ${ }^{3}$ Pós-doutoranda em Ciência e Tecnologia dos Alimentos, Universidade Federal de Santa Maria, RS, Brasil \\ cristianefc@hotmail.com \\ ${ }^{4}$ Professor Adjunto do Centro de Ciências Rurais da Universidade Federal de Santa Maria, Universidade Federal \\ de Santa Maria, RS, Brasil \\ cristiano.ufsm@gmail.com
}

\begin{abstract}
Resumo
Os alimentos funcionais contendo probióticos estão sendo produzidos em grande demanda devido à crescente conscientização dos consumidores em manter uma alimentação saudável. No entanto, o principal problema éa baixa sobrevizência destes microrganismos em produtos alimentares e no trato gastrointestinal. A microencapsulação é uma alternativa para a proteção de um bioativo e na modulação de sua liberação até o local de ação. Com isso, a técnica de gelificação internalemusificação surge como uma método viável pois consegue maior controle e redução do diâmetro da partícula; produção das micropartículas em temperatura próxima da ideal para a viabilidade probiótica entre outros benefícios. Neste contexto, o objetivo deste trabalho é fornecer uma revisão sobre a os benefícios das culturas probióticas e a importância da microencapsulação para melhorar a viabilidade destes microrganismos destacando os princípios do método de emulsificação/gelificação iônica interna.
\end{abstract}

Palavras-chave: Probióticos. Microencapsulação.Emulsificação.

\begin{abstract}
Functional foods containing probiotics are being produced in great demand due to the increasing awareness of consumers to maintain a healthy diet. However, the main problem is the poor survival of these microorganisms in food products and in the gastrointestinal tract. Microencapsulation is an alternative for protecting a bioactive and modulating its release to the site of action. Thus, the emulsification/internal gelation technical emerges as a viable method because it can better control and reduce particle size; production of microparticles in the optimal temperature for viability of the probiotic among other benefits. In this context, the aim of this study is to provide a review of the benefits of probiotic cultures and the importance of microencapsulation to improve the viability of these microorganisms highlighting the principles of emulsification/internal ionic gelation method.
\end{abstract}

Keywords: Probiotic. Microencapsulation. Emulsification. 


\section{Introdução}

Os probióticos são classificados como suplementos de microrganismos vivos, agrupados ou não, que são incorporados à dieta, influenciando de forma benéfica o desenvolvimento e manutenção da microbiota intestinal do hospedeiro quando administrados em quantidades adequadas (HOLZAPFEL \& SCHILLINGER, 2002; BRASIL, 2008; REIG; ANESTO, 2002).

Os pré-requisitos necessários para o uso comercial dos microrganismos probióticos são a sua sobrevivência, em número suficientemente elevado, durante a produção e estocagem e à passagem pelo trato gastrintestinal superior (ANNAN et al., 2008; KAILASAPATHY \& CHIN, 2000; MARTONI et al., 2008). A quantidade mínima viável de microrganismos probióticos deve estar situada entre 6 e 7 log UFC na recomendação diária do produto pronto para o consumo, conforme indicação do fabricante (BRASIL, 2008).

Os efeitos dos probióticos na saúde são inúmeros, tais como: melhora na digestibilidade de alguns nutrientes dietéticos, tais como proteínas e gorduras; aliviar os sintomas de intolerância a lactose; modulação de reações alérgicas através do desenvolvimento da função de barreira da mucosa; Tratamento de muitos tipos de diarreia tanto de adultos como em crianças; Preservação da integridade do intestino e combate a doenças inflamatórias como síndrome do intestino irritável, colite e doença hepática alcoólica; Aumento nos níveis de citocinas e imunoglobulinas e consequentemente aumento da resposta imune; Inibição de patógenos, reduzindo a chance de infecção (FERREIRA, 2009; SALMINEN et al., 1998, SINGH et al., 2011;).

Os probióticos devem ser seguros e conter em número suficiente no momento do consumo (SINGH, et. al., 2011; FAO/WHO, 2001). Mas em alguns condições como baixo $\mathrm{pH}$, alta acidez, presença de sais biliares, choques térmicos causados por atomização ou congelamento, o oxigênio molecular para microrganismos anaeróbicos e trato gastrointestinal humano representam um ambiente desafiador para a sobrevivência desses microrganismos (ANNAN et. al., 2008; CORCORAN et. al., 2005; CHEN \& MUSTAPHA, 2012; CHEOW et. al., 2014) Para isso, a concentração destas bactérias deve ser significativa no produto para que a ação de colonizar e proliferar aconteça e o efeito benéfico no intestino ocorra (TRIPATHI \& GIRI, 2014; DUNCAN \& FLINT, 2013).

Diversas pesquisas têm focado a proteção e viabilidade das culturas probióticas durante a produção, armazenamento e passagem do produto probiótico pelo trato gastrintestinal. Os estudos têm mostrado que as culturas podem ser significativamente protegidas através da técnica de microencapsulação e de imobilização em uma série de substratos (ROSS; DESMOND; STANTON, 2005).

Atualmente, a quantidade de métodos de microencapsulação patenteados ascende a várias centenas, e é previsível que esse número continue crescendo à medida que forem surgindo novos materiais encapsulantes e novos princípios ativos que requeiram processamentos específicos para a sua microencapsulação (VILA JATO, 2001). A gelificação iônica interna é uma técnica inovadora para a produção de micropartículas de polissacarídeo iônico. Este método é rápido, facilmente escalado e utilizada materiais biocompatíveis (CAI, et. al., 2014).

\section{Técnicas de microencapsulação}

De acordo com Jamekhorshid et al. (2014), atualmente, há inúmeros métodos de microencapsulação patenteados e cada vez mais em ascendência. É previsível que esse número continue crescendo à medida que forem surgindo novos materiais encapsulantes e novos princípios ativos que demandem processamentos específicos para a encapsulação. Dependendo da técnica utilizada leva a microcápsulas com morfologia diferente, estrutura e propriedades térmicas.

As micropartículas é o nome usual para as partículas sólidas que têm diâmetro de 1 a $1000 \mu \mathrm{m}$. Essas podem ser classificadas em 
microcápsulas (sistema reservatório) ou microesferas (sistema matriz) conforme a Figura 1. Nesse caso, as microcápsulas possuem o material ativo rodeado por um invólucro de polímero, enquanto nas microesferas a fase interna é molecularmente dissolvida ou heterogeneamente dispersa no polímero da matriz (NORDSTIERNA et al., 2010; FÁVAROTRINDADE et al., 2008; PIMENTEL et al., 2007).

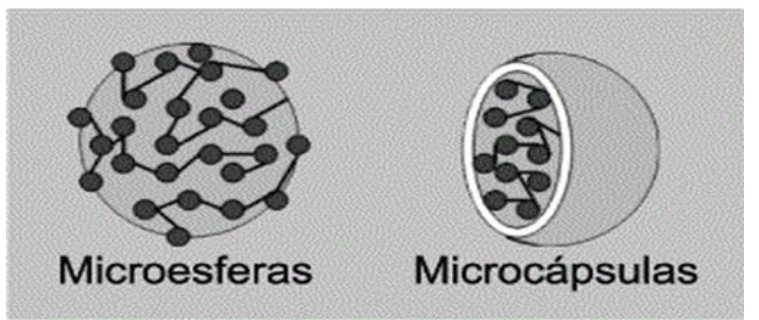

Figura 1 - Esquema ilustrativo diferenciando os dois tipos de micropartículas. Adaptado de PIMENTEL et. al., 2007.

As microcápsulas podem ser projetadas para liberar o material encapsulado em quantidades gradativas e em condições de meio específicas (como por exemplo, em diferentes partes do corpo). Diferentes tipos de "gatilho" podem ser utilizados para a liberação do material encapsulado tais como alteração de $\mathrm{pH}$, ruptura mecânica, temperatura, ação enzimática, força osmótica, entre outras (GOUIN, 2004; MAESTRELLI et al., 2008).

Os métodos mais comumente utilizados para o aprisionamento de substâncias são (SANTOS et al., 2001; LAM \& GAMBARI, 2014):

1) Processos químicos: Inclusão molecular e polimerização interfacial.

2) Processos físico-químicos: Coacervação simples e complexa, emulsificação seguida de evaporação do solvente, pulverização em agente formador de reticulação e envolvimento lipossômico.

3) Processos físicos: spray cooling, spray drying, pulverização em banho térmico, leito fluidizado, extrusão em centrífuga com múltiplos orifícios, cocristalização e liofilização.

\section{Emulsificação/gelificação iônica interna}

A emulsificação tem sido aplicada com sucesso na microencapsulação de bactérias ácido-láticas (DOLEYRES \& LACROIX, 2005). Neste método as cápsulas são formadas a partir de duas etapas: a dispersão de uma fase aquosa, contendo as células bacterianas e uma suspensão polimérica, dentro de uma fase orgânica, como óleo, resultando em uma emulsão de água em óleo e a solidificação das cápsulas por um agente geleificante. A emulsificação resulta em cápsulas de pequenos diâmetros, além de ser facilmente aplicada em grande escala. O óleo residual nas cápsulas, no entanto, pode não ser adequado para o desenvolvimento de baixo teor de gordura de produtos alimentares aplicações (MORTAZAVIAN et al. 2007).

Para a encapsulação de células bacterianas viáveis, os materiais utilizados devem ser suaves e não-tóxicos. Para aplicações alimentares, óleos vegetais são usados como a fase contínua. Alguns estudos têm usado branco óleo leve parafina e óleo mineral. Os emulsionantes também são adicionados para formar uma emulsão mais estável, porque baixam a tensão superficial, resultando em partículas menores (KRASAEKOOPT et al., 2003). O polissacarídeo mais utilizado para o microencapsulamento de células bacterianas é o alginato de sódio. Alginatos com alto teor de ácido $\alpha$-L-gulurônico $(\mathrm{G})$ são preferíveis para a formação da cápsula devido a sua elevada estabilidade mecânica e tolerância para sais e agentes quelantes (NICETIC ET AL., 1999).

As vantagens de usar alginato como um agente encapsulante inclui:

- Não é reativo com o material a ser encapsulado (probióticos);

- Forma matrizes delicadas com cloreto de cálcio para segurar os microrganismos dentro da estrutura da cápsula;

- Não é afeta a viabilidade das bactérias durante a vida de prateleira; 
- Libera completamente no local de ação.

Algumas desvantagens são atribuídas a micropartículas de alginato. Por exemplo, eles são sensíveis a ambientes ácidos pois perdem a sua estabilidade mecânica nesses ambientes. Além disso, o gel de alginato é formado na presença de íons de cálcio, assim, a sua integridade é deteriorada quando sujeita a íons monovalentes ou quelantes (fosfatos, lactatos e citratos). Os defeitos mencionados podem ser resolvidos através da mistura de alginato com outros compostos de polímeros, revestimento do alginato com substâncias diferentes ou fazer alguma modificação estrutural do alginato (KRASAEKOOPT et al., 2003). No estudo de Homayouni et al. (2008) que microencapsularam Lactobacillus casei (Lc-01) e Bifidobacterium lactis (Bb-12) com amido resistente por emulsificação adicionado em sorvere e concluíram que ocorreu uma redução próxima de $1 \log$ na temperatura de $-20^{\circ} \mathrm{C}$ após 180 dias de armazenamento. Já no estudo de Zou et al. (2011) que produziram microesferas de alginato contendo Bifidobacterium bifidum F-35 preparada por emulsificação/gelificao interna foram reforçadas por mistura com amido ou pectina ou de revestimento com quitosano ou poli-L-lisina para proporcionar uma proteção adicional para os microrganismos obtiveram uma eficiência de encapsulação de $43-50 \%$.

Outros vários agentes gelificantes incluindo carragena, carboximetilcelulose de sódio, acetato ftalato de celulose (CAP), quitosana, gelatina, proteína do grão de bico foram testados e apresentaram grande capacidade de formação de gel. Os resultados mostraram um gel firme com boa estabilidade mecânica e libertação fácil das bactérias encapsuladas em tampão alcalino (NICETIC et al., 1999; MARTÍN et al., 2015).

Para o preparo das micropartículas pelo método de emulsificação/gelificação interna é necessário o conhecimento da concentração de alginato, velocidade de rotação da emulsão e concentração de emulsificante (AHMED et al., 2013). A natureza e a concentração destes fatores influenciam a distribuição e o tamanho da partícula e consequentemente na viabilidade do microrganismo em estudo (MARTIN et al., 2013). Para aplicações em alimentos, o diâmetro médio das micropartículas, é uma das características mais importantes, sendo que estas devem ser suficientemente pequenas, para evitar um impacto sensorial negativo, sendo o tamanho desejável de aproximadamente $100 \mu \mathrm{m}$ (COSTA et al., 2015; HEIDEBACH, FÖRST, \& KULOZIK, 2009).

Diversos estudos indicam que a eficiência de encapsulação se mostra elevada na técnica de emulsificação/gelificação interna. A levedura probiótica, S. boulardii foi encapsulada em microesferas de alginato de cálcio preparadas pelo método de emulsificação com inulina e mucilagem como materiais de revestimento. As células encapsuladas apresentaram eficiência de encapsulação superior a 70\% durante 35 dias de armazenamento (ZAMORA-VEGA et al., 2012). Em outro estudo realizado por Özer et al. (2008) que encapsularam as culturas probióticas de B. bifidum e L. acidophilus por extrusão e emulsificação retrataram uma alta viabilidade durante os 90 dias de armazenamento. Takei et al. (2008) que microencapsularam S. cerevisiae por emulsificação obtiveram eficiência de encapsulação superior a 50\% com a diminuição da proporção em peso da fase aquosa e da fase oleosa.

Comparado com extrusão, a emulsificação é mais viável no controle do tamanho de partículas e produção em larga escala (HOESLI et al, 2011; KRASAEKOOPT, BHANDAR e DEETH, 2003). Com a gelificação interna o problema da aglomeração das micropartículas não ocorre como encontrado na técnica de gelificação externa, devido à libertação lenta dos íons $\mathrm{Ca}^{+2}$ a partir de fontes de cálcio insolúveis em vez da adição de cloreto de cálcio solúvel diretamente. Portanto, produz microcápsulas menores e mais uniformes ideais para a encapsulação de compostos de alto peso molecular (PONCELET et al., 1999).

\section{Conclusão}

A emulsificação/gelificação iônica interna se torna uma técnica relevante e adequada para a produção de micropartículas de alginato de sódio com probióticos. Esta técnica mostra uma potencial execução prática, com relativa facilidade de escalonamento, baixo custo operacional e pode utilizar materiais biocompatíveis, conferindo uma alternativa 
viável e vantajosa para a microencapsulação de probióticos para aplicação em alimentos.

\section{Referências}

AHMED, M. M., EL-RASOUL, S. A., AUDA, S. H., IBRAHIM,M. A. Emulsification/internal gelation as a method for preparation of diclofenac sodium-sodium alginate microparticles, Saudi Pharmaceutical Journal, 21 (1), p. 61-69, 2013.

ANNAN, N.T.; BORZA, A.D.; HANSEN, L. T. Encapsulation in alginate-coated gelatin microspheres improves survival of the probiotic Bifidobacterium adolescentis 15703T during exposure to simulated gastrointestinal conditions, Food Research International, V. 41, N. 2, p. 184-193, 2008.

BRASIL. Ministério da Saúde. Agência Nacional de Vigilância Sanitária. Resolução RDC no 2, de 07 de janeiro de 2002. Aprova o Regulamento Técnico de Substâncias Bioativas e Probióticos Isolados com Alegação de Propriedades Funcional e ou de Saúde. Diário Oficial da União, Brasília, 09 jan. 2002.

CAI, S. et. al. Microencapsulation of Lactobacillus acidophilus CGMCC1.2686 via emulsification/internal gelation of alginate using Ca-EDTA and $\mathrm{CaCO}_{3}$ as calcium sources, Food Hydrocolloids, V. 39, p. 295300, 2014.

CHEN, M.; MUSTAPHA, A. Survival of freeze-dried microcapsules of $\alpha$-galactosidase producing probiotics in a soy bar matrix, Food Microbiology, V. 30, n. 1, p.68-73, 2012.

CHEOW, W. S.; KIEW, T. Y.; HADINOTO, K. Controlled release of Lactobacillus rhamnosus biofilm probiotics from alginate-locust bean gum microcapsules, Carbohydrate Polymers, V. 103, p. 587-595, 2014.

CORCORAN, B.M.; STANTON C., FITZGERALD, G.F., ROSS, R.P. Survival of probiotic lactobacilli in acidic environments is enhanced in the presence of metabolizable sugars. Applied and Environmental Microbiology, v. 71, pp. 3060-3067, 2005.

COSTA, J. M. G., SILVA, E. K., HIJO, A. A. C. T., AZEVEDO, V. M., MALTA, M. R., ALVES, J. G. L. F., BORGES, S. V. Microencapsulation of Swiss cheese bioaroma by spray-drying: Process optimization and characterization of particles, Powder Technology, 274, 296-304, 2015.

DOLEYRES, Y.; LACROIX, C. Technologies with free and immobilised cells for probiotic bifidobacteria production and protection, international dairy journal, v. 15, n. 10, p. 973988.

DUNCAN, S. H.; FLINT, H. J. Probiotics and prebiotics and health in ageing populations, Maturitas, V. 75, n. 1, p. 44-50, 2013.

FAO/WHO. Health and nutritional properties of probiotics in food including powder milk with live lactic acid bacteria. Córdoba: FAO/WHO, 2001.

FÁVARO-TRINDADE, C.S et al. Revisão: microencapsulação de ingredientes alimentícios. Brazilian Journal of Food Technology, v.11, n.2, p.103-112, 2008.

FERREIRA, C. L. L. F. Benefícios das culturas lácticas probióticas. In: OLIVEIRA, M. N. (Org.). Tecnologia de produtos lácteos funcionais. São Paulo: Atheneu Editora, cap. 6, p. 213-234, 2009.

GOUIN, S. Microencapsulation: industrial appraisal of existing technologies and trends. Food Science and Technology, v. 15, p. 330347, 2004.

HEIDEBACH, T., FÖRST, P., KULOZIK, U. Microencapsulation of probiotic cells by means of rennet-gelation of milk proteins, Food Hydrocolloids, v. 23 (7), p. 1670-1677, 2009.

HOESLI, C. A., RAGHURAM, K., KIANG, R. L. J., MOCINECOVÁ, D., HU, X., JOHNSON, 
J. D., et al. Pancreatic cell immobilization in alginate beads produced by emulsion and internal gelation. Biotechnology and Bioengineering, 108(2), 2011.

HOLZAPFEL, W.H.; SCHILLINGER, U. Introduction to pre- and probiotics. Food Res. Int., Amsterdam, v.35, n.2/3, p.109-116, 2002.

HOMAYOUNI, A.; AZIZI, A.; EHSANI, M.R.; YARMAND, M.S.; RAZAVI, S.H. Effect of microencapsulation and resistant starch oh the probiotic survival and sensory properties of symbiotic ice cream. Food chemistry, v. 111, n. 1, p. 50-55, 2008.

JAMEKHORSHID, A.; SADRAMELI, S.M.; FARID, M. A review of microencapsulation methods of phase change materials (PCMs) as a thermal energy storage (TES) medium, Renewable and Sustainable Energy Reviews, v. 31, p. 531-542, 2014.

KAILASAPATHY, K., CHIN, J. Survival and therapeutic potential of probiotic organisms with reference to Lactobacillus acidophilus and Bifidobacterium spp. Immunol. Cell Biology. 78: 80-88, 2000.

KRASAEKOOPT, W.; BHANDARI, B.; DEETH, H. Review: Evaluation of encapsulation techniques of probiotics for yoghurt. International Dairy Journal, v. 13, p. 3-13, 2003.

LAM, P.L.; GAMBARI, R. Advanced progress of microencapsulation technologies: In vivo and in vitro models for studying oral and transdermal drug deliveries, Journal of Controlled Release, v. 178, p. 25-45, 2014.

MAESTRELLI, F.; CIRRI, M.; CORTI, G.; MENNINI, N.; MURA, P. Development of enteric-coated calcium pectinate microspheres intended for colonic drug delivery. European Journal of Pharmaceutics and Biopharmaceutics, v. 69,n. 2, p. 508-518, 2008.

MARTIN, M. J., LARA-VILLOSLADA, F., RUIZ, M.A., MORALES, M.E. Effect of unmodified starch on viability of alginateencapsulated Lactobacillus fermentum CECT5716, LWT - Food Science and Technology, 53 (2), 480-486, 2013.

MARTÍN, M. J., LARA-VILLOSLADA, F., RUIZ, M. A., MORALES, M. E. Microencapsulation of bacteria: A review of different technologies and their impact on the probiotic effects, Innovative Food Science \& Emerging Technologies, v. 27, p. 15-25, 2015.

MARTONI, C., BHATHENA, J., URBANSKA, A. M., PRAKASH, S. Microencapsulated bile salt hydrolase producing Lactobacillus reuteri for oral targeted delivery in the gastrointestinal tract. Applied Microbiology Biotechnology, v. 81, n. 2, p. 225-233, 2008.

MORTAZAVIAN, A. M.; RAZAVI, S. H., EHSANI, M. R.; SOHRABVANDI, S. Principles and methods of microencapsulation of probiotic microorganisms. Iranian Journal of Biotechnology, v. 5, p. 1-18, 2007.

NICETIC, M., KAILASAPATHY, K., AND TARASOFF, L. Mechanical stability of food gum gels for immobilisation of probiotic bacteria. The $8^{\text {th }}$ Intl. Workshop on Bioencapsulation: Recent progress in research and Technology, Norway, Sept. 13-15, Abstract, P11, 1999.

NORDSTIERNA, L. et. al. Comparison of release behaviour from microcapsules and microspheres, Progress in Organic Coatings, v. 69 , n. 1, p. 49-51, 2010.

ÖZER, B., UZUN, Y.S., KIRMACI, H.A. Effect of microencapsulation on viability of Lactobacillus acidophilus LA-5 and Bifidobacterium bifidum BB-12 during kasar cheese ripening, International Journal of Dairy Technology, 61 (3), pp. 237-244, 2008.

PIMENTEL et. al. Nanotecnologia farmacêutica aplicada ao tratamento da malária. Rev. Bras. Cienc. Farm. [online], vol.43, n.4, pp. 503-514, 2007. 
PONCELET, D., BABAK, V., DULIEU, C., PICOT, A. A physico-chemical approach to production of alginate beads by emulsification-internal ionotropic gelation, Colloids and Surfaces A: Physicochemical and Engineering Aspects, v. 155, n. 2-3, p. 171176, 1999.

REIG, A. L. C.; ANESTO, J. B. Prebióticos y probióticos, una Relación Beneficiosa. Instituto de Nutrición e Hiene de los Alimentos. Revista Cubana de Alimentação e Nutrição. v. 16, n. 1, p. 63-8, 2002.

ROSS, R.P.; DESMOND, C.; STANTON, C. Overcoming the technological hurdles in the development of probiotic foods. J. Appl. Microbiol., v.98, p.1410-1417, 2005.

SALMINEN, et al. Demonstration of safety of probiotics-a review. Int J Food Microbiol; 44: 93-106, 1998.

SANTOS, A. B.; FERREIRA, V. P.; GROSSO, C. R. F. Microcápsulas: uma alternativa viável. Biotecnologia Ciência e Desenvolvimento, Brasília, ano 3, n. 16, p. 2630, 2001.

SINGH, et. al. Probiotics: A review, Asian Pacific Journal of Tropical Biomedicine, V.1, n. 2, Supplement, p. S287-S290, 2011.

TAKEI T., YOSHIDA M., HATATE Y., SHIOMORI K., KIYOYAMA S. Lactic acid bacteria-enclosing poly(epsilon-caprolactone) microcapsules as soil bioamendment. J Biosci Bioeng, v. 106(3), p. 268-72, 2008.

TRIPATHI, M.K.; GIRI, S.K. Probiotic functional foods: Survival of probiotics during processing and storage, Journal of Functional Foods, V. 9, p. 225-241, 2014.

VILA JATO, J. L. Tecnologia farmacêutica: formas farmacêuticas. Madrid. Editorial Sintesis, v. 1-2, 2001.

ZAMORA-VEGA， R., MONTAÑEZ-SOTO, J.L., MARTÍNEZ-FLORES, H.E., FLORES-
MAGALLÓN, R., MUÑOZ-RUIZ, C.V., VENEGAS-GONZÁLEZ, J., ORTEGA, T.D.J. A. Effect of incorporating prebiotics in coating materials for the microencapsulation of Sacharomyces boulardii. International Journal of Food Sciences and Nutrition, 63 (8), pp. 930-935, 2012.

ZOU, Q.,ZHAO, J.,LIU, X.,TIAN, F.,ZHANG, H.,ZHANG, H., CHEN, W. Microencapsulation of Bifidobacteriumbifidum F-35 in reinforced alginate microspheres prepared by emulsification/ internal gelation, International Journal of Food Science \& Technology, 46 (8), 1672-1678, 2011. 